\title{
EL MARIDAJE FÚTBOL / RADIODIFUSIÓN EN LAS ISLAS CANARIAS DURANTE EL FRANQUISMO, 1939-1975
}

DOI: http://dx.doi.org/10.12795/RiHC.2015.i05.10

Julio Antonio Yanes Mesa

Universidad de La Laguna

jayanes@ull.edu.es

Recibido: 20-9-2015

Aceptado: 18-10-2015

Resumen: En el presente texto examinamos la estrecha relación que la radio ha mantenido con el fútbol en un espacio muy concreto de España durante el franquismo (1939-1975), el archipiélago canario, al objeto de sacar a la luz sus especificidades en el sistema informativo español. A tal fin, hemos recabado el mayor número de datos posible en las fuentes más diversas para, engarzando unos con otros, reconstruir los hechos y, a la luz de la bibliografía disponible, detectar el hecho diferencial isleño en el contexto estatal. La investigación ha dejado patente que, junto con las rémoras derivadas de la lejanía y la insularidad, las islas atesoran una realidad muy singular por su condición extra-peninsular que, aunque rezagada por las limitaciones contextuales, enriquece los conocimientos de la historia de la radio española.

Palabras clave: radiodifusión; fútbol; franquismo; Islas Canarias; centro-periferia. 
Abstract: In this article we examine the strong relationship that broadcasting has maintained with soccer in a very specific space of Spain during the Franco regime (1939-1975), the Canary Islands, in order to detect the insular specificities on the Spanish informative system. With that aim in view, we have seeked the largest amount of data possible in many diverse sources for, linking one to another, rebuild the facts and, on the basis of available bibliography, detect the insular differential fact on the Spanish context. The research has demonstrated that, together with the obstacles derived from distance and insularity, the Canary Islands possess a very singular reality that, although conditioned by the contextual limitations, it enhances the knowledge of the history of broadcasting in Spain.

Keywords: broadcasting; soccer; Franco regime; Canary Islands; center-outskirts.

\section{Estado de la cuestión, fuentes y metodología}

Sin duda alguna, las Islas Canarias han conformado históricamente el subsistema comunicativo más singular del actual territorito del estado español, lo que no podía ser de otra manera dado su emplazamiento "ultraperiférico», a un millar y medio de kilómetros de la península; su tardía incorporación, a finales del siglo $\mathrm{XV}$, al mundo occidental; y sus tradicionales lazos económicos con el área de la libra esterlina y culturales, por la emigración, con Latinoamérica. Por ello, a la hora de abordar históricamente cualquier vertiente de la realidad en España, el archipiélago demanda una atención específica, más aún cuando se trata de temas que, como la comunicación social, están tan enhebrados en el contexto social al intervenir en el proceso una variable cultural tan cambiante de un lugar a otro como la idiosincrasia de cada comunidad receptora. Si a tales razones añadimos el creciente predicamento que, desde el último cuarto de siglo de la centuria anterior, se ha ganado la investigación centrada en objetos de estudio concretos y aprehensibles desde perspectivas globales para hacer frente a los desafíos metodológicos del posmodernismo (Breisach, 2009: 14-43), debemos convenir que la propuesta es incluso pertinente, a partir de microespacios bien delimitados, para la península, más aún cuando esta atesora una acusada diversidad cultural por encima de la continuidad geográfica. Por si fueran pocas las ventajas científicas de este planteamiento, con los resultados de tales trabajos estaríamos en disposición de renovar las perspectivas reducciones de la historia de la radio española centrada en lo acontecido en Madrid, Barcelona y los restantes enclaves urbanos más desarrollados del Estado.

En los renglones que siguen, nos hemos propuesto detallar los inicios y el proceso evolutivo de un capítulo muy concreto de las ondas hertzianas durante la dictadura franquista, el fútbol como eje central de las «sinergias crecientes» (Moragas, 1994) 
que entre el deporte y la radiodifusión jugó en la España franquista, en el heterodoxo contexto que, por las razones geográficas e históricas citadas, configuran las Islas Canarias. A tal fin, y siguiendo las pautas metodológicas de la microhistoria italiana (Levi, 1999: 119-143; Aguirre Rojas, 2014: 15-204;), hemos recopilado el mayor número de datos posible en las fuentes disponibles, tanto hemerográficas ${ }^{1}$ como archivísticas $^{2}$ y orales, ${ }^{3}$ cotejado el material recabado a la luz del estado de la cuestión ${ }^{4}$ $y$, sobre el corpus empírico que pasó la criba, hilvanado las inferencias que entrelazan los fragmentos de realidad rescatados del pasado. En pos del objetivo trazado, hemos procurado reconstruir los hechos con la mayor precisión posible sin perder la referencia del contexto estatal para detectar las singularidades isleñas y, con ello, aportar un granito de arena a esa renovada Historia de la Radio Española en la que todas las particularidades territoriales del Estado reclaman su protagonismo.

\section{Los hitos inaugurales del deporte en las ondas hertzianas isleñas}

En la etapa preliminar de onda corta (1925-1934), en la que los promotores del medio en la isla emitieron al margen de la ley con un equipo artesanal, la radiodifusión canaria apenas prestó atención a las actividades lúdicas y gimnásticas que, por entonces, estaban empezando a despuntar al calor de las mejoras socioeconómicas traídas por el crecimiento económico de los «felices» años veinte (Suárez Bosa, 1996).

\footnotetext{
${ }^{1}$ Nos referimos a los tres rotativos de la provincia occidental del archipiélago, donde estaban domiciliadas las emisoras estudiadas, El Día (1939...), La Tarde (1927-1981) y Diario de Avisos de Santa Cruz de La Palma (1890-1976), al órgano falangista Amanecer (1937-1939), al semanario deportivo Aire Libre (1943-1965) y a la revista especializada Radio Tenerife (1935-1936).

${ }^{2}$ En concreto, el Archivo General de la Administración de Alcalá de Henares, el Archivo Histórico Provincial de Santa Cruz de Tenerife y los archivos municipales de Santa Cruz de Tenerife, La Orotava, Güímar, Santa Cruz de La Palma y, para temas puntuales, otras localidades isleñas.

${ }^{3}$ Los datos más relevantes nos los facilitaron, en entrevistas efectuadas entre los años 2007 y 2012, Juan Antonio Rolo Hernández (13/04/1934) de Radio Club Tenerife; José Antonio Pardellas Casas (27/01/1938), César Fernández-Trujillo de Armas (24/06/1937), Juan Petronilo Hernández García (31/05/1946) y Manuel Negrín Ruiz (22/10/1955) de Radio Juventud de Canarias; José Ramos González (20/02/1931) y Clemente Mesa Curbelo (23/11/1944) de Radio Popular de Güímar; José Siverio Pérez (29/11/1928), Carlos Argüelles García (24/03/1925) y Juan Cruz Ruiz (27/09/1949) de La Voz del Valle de La Orotava; y Pedro Cobiella Cuevas (10/09/1930) y Julio Marante Díaz (16/04/1950) de La Voz de la Isla de La Palma.

${ }^{4}$ Ante el enorme volumen de la información recabada y el limitado espacio del que disponemos para exponer los resultados de la investigación, en lugar de detallar aquí pormenorizadamente el estado de la cuestión, hemos preferido colocar las oportunas referencias en los lugares en los que hacemos alusión a las peculiaridades isleñas más relevantes.
} 
En plena República, tendrían que darse dos novedades, una contextual derivada del desarrollo urbano de la capital insular y otra técnica relacionada con la mejora de la señal, para que el tema que nos ocupa irrumpiera en una parrilla de la programación que, en coherencia con el millar escaso de aparatos receptores instalados y la reducción de la audiencia, estaba copada por la cultura de élite en la acepción más exquisita del término. De un lado, la consolidación de las primeras manifestaciones de la cultura de masas en las dos capitales provinciales y los núcleos más urbanizados del archipiélago, con el fútbol como uno de sus pilares más fundamentales. De otro, la puesta en marcha de un equipo legalizado de onda media merced al decretode 8 de diciembre de 1932 (Gorostiaga, 1976) que, para extender la cobertura geográfica de la radiodifusión en España, abrió las puertas a la concesión de emisoras de baja potencia con tal tipo de banda a las pequeñas ciudades que carecían del medio o, como en los casos de Santa Cruz y Las Palmas, habían echado mano de la onda corta a espaldas de la legislación vigente. Ambas circunstancias, pues, se aunaron para que el 22 de febrero de 1934, casi siete años después que en la península (Ezcurra, 1974: 208), las ondas hertzianas retransmitieran el primer partido de fútbol en las islas, desde este primer episodio, en medio de una enorme expectación.

En concreto, se trató de la final de unas eliminatorias que, dentro del período de pruebas del instrumental de onda media recientemente adquirido, se autorizó en atención a las insistentes demandas del público porque, tras haber sido suspendida con anterioridad por los graves incidentes acaecidos en su transcurso, se iba a celebrar a puerta cerrada en la capital insular. Los dos conjuntos de más solera de la isla, el CD Tenerife y el Real Unión de Santa Cruz, con la disputa de la participación en un torneo en representación de Canarias, fueron los protagonistas del histórico evento, al igual que Juan Lubary, el tesorero de la junta directiva de la sociedad que sostenía la emisora, quien comentó el desarrollo del evento con un micrófono conectado al equipo emisor a través de las líneas telefónicas. Según reflejó La Tarde (1934, 22 de febrero, p. 2) y la restante prensa de la época, el improvisado speaker tuvo enormes dificultades para detallar a la audiencia lo sucedido en el terreno de juego porque los ánimos estaban muy encrespados entre los jugadores e, incluso, los seguidores de ambos cuadros, muchos de los cuales consiguieron burlar la vigilancia y acceder a hurtadillas al recinto. El clima de crispación se agravó desde que el CD Tenerife marcó el primer gol, hasta el extremo de obligar al árbitro a suspender el partido a inicios de la segunda parte, lo que provocó la invasión del campo y el estallido de una reyerta entre ambas aficiones que, a duras penas, consiguieron sofocar las fuerzas de orden público. Tanto los masivos corros formados por los jóvenes y adultos en torno a los escasos receptores instalados en la isla, como las pasiones que en días sucesivos desvelaron las crónicas periodísticas, dejaron patente desde fechas tan tempranas el formidable gancho que para atraerse al segmento masculino de los potenciales oyentes ya suponía el fútbol. 
A partir de entonces, una vez inaugurada oficialmente la estación de onda media, la ahora Radio Club Tenerife EAJ-43 siempre estuvo presente en los enfrentamientos más decisivos de todas las competiciones futbolísticas insulares mientras se mantuvo el régimen republicano. Así, el mismo año 1934, la afición tinerfeña tuvo la oportunidad de escuchar por vez primera, también vía telefónica, la retransmisión de un derbi regional, el que libraron en Gran Canaria el CD Tenerife y el CD Marino de Las Palmas, lo que volvió a movilizar a los oyentes varones hasta cotas desconocidas por entonces. ${ }^{5}$ Meses más tarde, ya en el tramo final de la República, el colaborador Andrés Llombet ponía en antena unas Charlas deportivas con periodicidad semanal abiertas a las restantes modalidades practicadas en la época, todas muy minoritarias y elitistas salvo la lucha canaria, las cuales debieron constituir el primer espacio del género emitido con cierta regularidad en la programación. Luego, tras el colapso que para las competiciones locales supuso el estallido de la guerra civil, la decana de las emisoras canarias retransmitió, a finales de enero de 1938, el primer partido de la selección española de fútbol, el jugado en Lisboa entre un combinado de la zona ocupada por los golpistas con la Portugal de Oliveira Salazar, según recogió el diario falangista Amanecer (1938, 29 de enero), a través de la reproducción de la señal de Radio Nacional de España. Pero aquella apertura al exterior de la información deportiva sólo fue flor de un día porque, en la inmediata posguerra, el ámbito de esta temática tan popular de la parrilla de la programación volvió a reducirse al contexto insular.

\section{El deporte en los oscuros años de la autarquía}

Durante la II Guerra Mundial, Radio Club Tenerife consolidó la presencia en la parrilla de la programación al deporte, capítulo que, a pesar de su simple condición de actividad de ocio, tampoco pudo zafarse del asfixiante corsé que, sobre todo, en el primer franquismo, contrajo los márgenes de actuación de los periodistas españoles hasta límites realmente grotescos. En este caso, las instrucciones que llegaban de Madrid obedecían a la obsesión del régimen por aparentar que toda la población española secundaba, con unanimidad y camaradería, el orden de cosas impuesto por el general Franco, lo que se traducía en una serie de consignas que tenían por finalidad «enfriar» la rivalidad existente entre Tenerife y Gran Canaria, implantar un lenguaje

\footnotetext{
${ }^{5}$ Detalles muy minuciosos de este y otros acontecimientos de la etapa inaugural de la radiodifusión isleña ofrecen las páginas del mensuario Radio Tenerife, editado en la capital provincial en 1935 y 1936.
} 
"cortés ycaballeroso» entre los informadores y erradicar de las crónicas las referencias a los actos «inapropiados» que afloraban en las competiciones (Sinova, 1989: 256-261). La nota informativa que la Federación Tinerfeña de Fútbol dirigió a los aficionados tinerfeños en el rotativo El Día (1942, 2 de mayo, p. 2) en respuesta al «alto sentido que Falange Española ha impreso (sic) a los torneos deportivos de España», resulta sumamente ilustrativa para entrever hasta qué punto, no sólo los periodistas sino también los deportistas y los espectadores, tuvieron que reprimirse por entonces en los estadios: "Los clubes de Las Palmas que visiten nuestra isla han de ser recibidos con el calor y el aplauso a que obligan nuestra tradicional hospitalidad y corrección, y de seguro que en la vecina isla no ha de faltar esa reciprocidad». Al margen de tales servidumbres, del elitismo y de la reducción de las modalidades practicadas por los jóvenes de las clases populares, prácticamente, al fútbol y la tradicional lucha canaria, el deporte estaba imbuido por entonces de un concepto patriótico que hacía de este una actividad antitética a la actual.

Sobre tales bases, Radio Club Tenerife siguió retransmitiendo los partidos más decisivos de las competiciones insulares, al igual que otros no menos atractivos como el disputado, en el verano de 1942, por el representativo provincial con el Atlético Aviación en la primera visita que el cuadro madrileño hizo a la isla. Junto al fútbol, la coyuntura más favorable para los intermitentes ciclos de conferencias en los que se trataban los deportes minoritarios llegó a raíz de los éxitos de la natación canaria en los campeonatos de España celebrados en Palma de Mallorca en el verano de 1941. A título orientativo, los conferenciantes y los tópicos tratados en aquella ocasión fueron los siguientes: Andrés Llombet, boxeo, cuya federación presidía; Enrique Maffiotte, gimnasia sueca, baloncesto y "otras modalidades»; Julio Fernández, natación; José Alberto Santana, lucha canaria; Fernando Marín, tenis, del que era delegado federativo; Domingo Rodríguez, fútbol; y Ángel Acosta, ajedrez. ${ }^{6}$ Antes de un mes, el 5 de octubre de 1941, fue programado un espacio dominical en el que se abordaron los mismos temas bajo la dirección de Andrés Llombet y Domingo Rodríguez, al que luego siguieron unas "conferencias baloncestistas» y otros similares. Cuando la II Guerra Mundial tocaba a su fin, los deportes, al igual que todos los espacios radiofónicos, perdieron entidad sin solución de continuidad, en coherencia con la brutal degradación de la vida insular y, en general, española, por la superposición del impacto del aislamiento internacional a las graves secuelas dejadas en la España franquista por la guerra civil (Guerra Palmero, 2006: 161-295).

\footnotetext{
${ }^{6}$ Entre los intervinientes, pues, figuraban los pioneros de la prensa deportiva de la provincia de Santa Cruz de Tenerife, Julio Fernández Hernández (1912-2003) y Domingo Rodríguez González (1901-1971), fundadores respectivos de Aire Libre (1943-1965) y Jornada Deportiva (1953...), así como el destacado periodista y escritor Ángel Acosta Hernández (1900-1971), redactor-jefe del diario vespertino La Tarde (1927-1981), rotativo que informó con detalle de estas actividades radiofónicas (1939, 29 de junio, p. 4; y 1941, 6-13 de septiembre).
} 


\section{La inserción de la realidad isleña en la estatal de la mano del fútbol}

En coincidencia con la supresión de las cartillas de racionamiento, los ascensos de la UD Las Palmas en 1950 y, tres años más tarde, del CD Tenerife a la segunda división del fútbol nacional, abrieron el escenario de este capítulo de la programación al conjunto del estado español. Hasta entonces, los deportes habían acusado un acentuado divorcio entre las actividades desarrolladas en las islas, que eran las que cubría la emisora con sus propios medios, y la alta competición estatal en la que, normalmente, no había representación isleña, de la que se informaba a través de las noticias de la prensa. Pero ahora, la irrupción de los dos clubes representativos canarios en el fútbol estatal y el paralelo alivio de las penurias de la posguerra, se encargaron de que los espacios tradicionales centrados en las charlas divulgativas y las lecturas de los periódicos quedaran obsoletos. El salto experimentado por el fútbol fue tan acusado que, de inmediato, la categoría juvenil comenzó su andadura en las islas, al tiempo que los aficionados podían exteriorizar con mayor libertad sus pasiones, conforme el régimen relajaba su obsesión en aparentar que toda la población española estaba alineada unánimemente, sin la menor disidencia en el ámbito más trivial de la sociedad, detrás de los valores del franquismo. La apertura al exterior se consolidó con la natación, la otra modalidad en la que había la suficiente tradición en la crema social del archipiélago como para poder competir a escala estatal, lo que unido a la colaboración del locutor tinerfeño Juan Manuel Soriano desde la jefatura de la programación de Radio Nacional de España en Barcelona, hicieron posible que Radio Club Tenerife cubriera por vez primera, según reflejó el semanario Aire Libre (1954, 2 de agosto, p. 2), el campeonato nacional celebrado en el verano de 1954 en la ciudad condal.

Las retransmisiones de los partidos de fútbol desde la península a través de las líneas telefónicas o la reproducción de alguna señal que entraba en el archipiélago, no sólo abrieron la temática deportiva cotidiana al escenario estatal sino, además, a unas formas de hacer radio mucho más dinámicas. Nos referimos al innovador espacioCarrusel deportivo de la SER, que había aparecido en la temporada anterior a la del ascenso del CD Tenerife a la segunda división nacional, la 1952/53, ${ }^{7}$ que de inmediato emuló, aunque todavía en horario reducido, Tablero deportivo de Radio Nacional de España y, a partir de 1955, Domingo deportivo español de la REM (Balsebre, 2002: 325-342). El formato, basado en las novedades que desde los mismos terrenos de juego daban por teléfono, en conexión con el estudio, los corresponsales desplazados al efecto, «imprim(ía) a la acción informativa un ritmo frenético, inédito

\footnotetext{
${ }^{7}$ Desde 1951, se había autorizado la instalación del utillaje de las emisoras en los estadios para posibilitar la radiodifusión en cadena en la península y, con ello, lo que ArmandBalsebre ha denominado «futbolización de la vida española» (Balsebre, 2002: 327-342).
} 
hasta entonces, mediante los cambios sucesivos de voces y la repetición constante del protocolo informativo de minuto y resultado (...) al ritmo que marca la propia acción dramática del juego» (Balsebre, 2002: 131-134). El acceso en las islas a la radio, sin embargo, estaba todavía muy restringido por los pocos aparatos receptores disponibles y la reducción del sistema radiofónico insular a las dos estaciones privadas de baja potencia montadas en la República, Radio Club Tenerife EAJ-43 y Radio Las PalmasEAJ-50, ambas con áreas de cobertura muy cortas y, además, sin apoyaturas externas porque todavía no se habían incorporado a la SER. Para ilustrar las dificultades con las que llegaban las señales de la península por entonces, basta con echar un vistazo a la crónica publicada por La Tarde (1953, 25 de mayo, p. 2) sobre el partido de ida de la eliminatoria del ascenso a la segunda división del CD Tenerife en Orihuela, cuya «retransmisión, hecha a través de Alicante, ofrecía grandes dificultades», hasta el extremo de que "al final del primer tiempo fue roto el cable de la telefónica y quedó interrumpida». Aún así, con el acicate de la participación del representativo provincial en la categoría de plata del fútbol estatal, el locutor Gustavo Castellano Gámez puso en antena los jueves, a las 21:00 horas, el programa Mirador deportivo, con el que atrajo mucha audiencia masculina dando cancha, cada vez más, al fútbol de élite.

A pesar de todas las deficiencias técnicas, el seguimiento de la campaña del CD Tenerife en la segunda división nacional por las ondas hertzianas atraía tanto a los aficionados que, pronto, saltaron a la prensa las quejas de los equipos de las categorías regionales por la pérdida de espectadores, al preferir muchos de estos quedarse en los domicilios, bares y espacios de sociabilidad dotados del medio a escuchar el partido del cuadro blanquiazul, con la consiguiente merma en las ventas de las entradas. Tras una breve interrupción de las retransmisiones que, asimismo, generaron otra masiva oleada de protestas entre los radioescuchas, el problema se resolvió cuando la federación tinerfeña acordó con las partes implicadas gravar las localidades del estadio Heliodoro Rodríguez López y las cuotas de los socios del CD Tenerife con una y dos pesetas, respectivamente, para compensar a los conjuntos tinerfeños que jugaban a la misma hora que el representativo provincial. Aunque desconocemos el grado de cumplimiento y la duración del acuerdo, lo cierto es que, a partir de entonces, las retransmisiones de los partidos del cuadro blanquiazul no volvieron a generar protestas dentro de la isla. Otra cosa sucedió cuando, a finales de 1953, llegó el primer derbi canario de la historia en la categoría de plata del fútbol nacional, con el enfrentamiento entre el recién ascendido CD Tenerife y la UD Las Palmas. En efecto, en medio de una enorme expectación, las gestiones realizadas por las dos emisoras isleñas con ambos clubes y los organismos federativos para radiar el encuentro resultaron infructuosas ante la rotunda negativa del cuadro amarillo por «razones económicas», hasta el extremo de que incluso, según informó el semanario Aire Libre (1953, 28 de diciembre, p. 2), prohibió «anticipar informes antes de finalizar el partido». 
En definitiva, en paralelo a la progresiva superación del caos de la posguerra y los primeros conatos aperturistas del país al exterior, los espacios deportivos de la radiodifusión tinerfeña extendieron sus contenidos cotidianos al resto del Estado de la mano del fútbol $y$, en coyunturas muy concretas, la natación, con las tensiones internas inherentes a todo cambio hasta que, al final, se consiguieron adecuar los intereses de todas las partes implicadas en el proceso. Sobre tales bases, la radio se convirtió en un fuerte reclamo para los varones en las tardes dominicales al ofrecer sobre el terreno de juego, prestando especial atención al representativo provincial y, en menor medida, al rival grancanario, la marcha de la jornada en la primera y segunda división nacional en base a la información recabada de la península por las vías disponibles.

\section{La masculinización de la audiencia isleña con el gancho del fútbol}

Desde su puesta en marcha a finales de 1955, Radio Juventud de Canarias se distinguió por prestar una atención especial, no sólo al fútbol sino, a todas las modalidades practicadas en la época, incluyendo las minoritarias y las categorías juveniles, en coherencia con su empeño en ganarse, como todas las estaciones-escuelas de la Cadena Azul de Radiodifusión, al segmento más joven de la sociedad española. Un complemento de apoyo fundamental para tales aspiraciones fueron las pistas polideportivas de la llamada "ciudad juvenil», en una de cuyas alas se instaló la emisora, donde los monitores del Frente de Juventudes organizaban, aunque todavía con un número de jóvenes muy reducido, equipos de baloncesto, balonmano, voleibol y otras propuestas que, asimismo, eran desconocidas en la época para el gran público. El protagonismo de la mujer en estas lides quedó testimoniado en la nota que, a inicios de 1958, el rotativo La Tarde publicó (1958, 8 de enero, p. 7) sobre un programa dedicado por la estación-escuela al baloncesto femenino de la isla, en cuyo transcurso fueron entrevistadas algunas directivas y jugadoras. La diversificación temática, sin embargo, no restó al fútbol el absorbente papel que tenía en todas las emisoras de la época, tal y como dejara patente el perfil del responsable de la sección en la citada estación, el periodista Miguel Ángel Domínguez Hernández (Mínguez), uno de los más acreditados especialistas del archipiélago en la materia que, además, colaboraba en los diarios generalistas locales y en la prensa especializada del género incluyendo, como corresponsal, las cabeceras peninsulares Vida deportiva, Dicen y Lean.

En un principio, la estación-escuela cubría las tardes dominicales a posteriori, a partir de las 21:30 horas, como Radio Club Tenerife, con un programa titulado Antorcha deportiva, en el que, tras recabar con un receptor de onda corta la información 
pertinente de La Voz de Madrid, Mínguez daba los resultados, la quiniela y algunos comentarios sobre el desarrollo de la jornada. Luego, de manera paulatina, aparecieron varios espacios complementarios como Avance del domingo deportivo, que estaba en antena los sábados; Deportes hasta en la sopa, luego titulado Minutos deportivos, que era diario; y Juanito pronostica, que con ciertas dosis de humor llevaba el director del grupo de teatro Ignacio García-Talavera. No sería hasta la temporada 1957/58 cuando Mínguez y César Fernández-Trujillo pusieron en antena un programa propio de tarde bajo el título Olimpiada musical, en el que, sobre un fondo de música ligera, daban cuenta, entre las 15:30 a las 18:00 horas, del desarrollo en directo de las competiciones nacional y regional. A tal fin, los técnicos de la estación-escuela captaban la señal del espacio Domingo deportivo español de la REM con un receptor de onda corta que reproducían a través del equipo emisor propio, aunque teniendo la precaución de no dejar salir al aire la publicidad original, que era sustituida por otra captada en las islas, ni las indicaciones de las conexiones a los distintos campos, que locutaba el propio Mínguez tras escuchar, desconectado, el aviso correspondiente. Con prácticas fraudulentas similares se daba cuenta de los partidos de las categorías regionales, cuya fuente de información era el teléfono, dado que a menudo se hacía pasar por corresponsal desplazado a alguna localidad un miembro de la emisora que intervenía desde los propios estudios; y se utilizaba el célebre comentario de Matías Prats con el que se cerraba el espaciode la REM en la península, que César FernándezTrujillo grababa para ponerlo en antena el lunes por la noche, en un horario comprado a la emisora, con publicidad propia. ${ }^{8}$ Todo ello resulta explicable, de un lado, porque el régimen, tras cribar la información que circulaba en el país, era muy permisivo con la apropiación de lo ajeno que consideraba inocuo; y, de otro, porque el Centro Emisor del Atlántico de Radio Nacional de España no empezó a emitir hasta mediados de 1964.

La creciente penetración del futbol entre los jóvenes y adultos de todas las clases sociales culminó en la temporada 1960/61, cuando el CD Tenerife, tras una brillante campaña, ascendió a la primera división nacional para competir, nada menos que, con el Real Madrid de Di Stéfano y el CF Barcelona de Kubala. La expectación que suscitó la ilusionante trayectoria del equipo representativo de la provincia conforme avanzó el campeonato hizo que, en contraposición a los años anteriores, cuando los partidos jugados fuera del archipiélago se ofrecían a través de alguna señal foránea, las dos emisoras tinerfeñas desplazaran a sus propios locutores para brindar los encuentros más trascendentales a sus oyentes desde ópticas propias. Mínguez o César FernándezTrujillo, por Radio Juventud de Canarias, y Avelino Montesinos, por Radio Club Tenerife, fueron los primeros que viajaron expresamente desde la isla para asumir tal cometido; mientras el colega grancanario afincado por entonces en la península,

\footnotetext{
${ }^{8}$ Detalles suministrados por el propio César-Fernández Trujillo en la entrevista en profundidad que mantuvimos el 25 de enero de 2009.
} 
Antonio Lemus del Moral, que solía radiar los de la UD Las Palmas, se ocupaba de los restantes. Un dato tan frío como el incremento de los periodistas deportivos en todos los periódicos y emisoras del archipiélago, y otro tan anecdótico como la disputa del primer partido de fútbol benéfico entre las plantillas y los allegados de Radio Club Tenerife y Radio Juventud de Canarias en las Navidades de 1960 (Aire Libre, 1960, 5 de diciembre, p. 4), insisten en el salto cuantitativo y cualitativo que esta opción de ocio interclasista dio a partir de entonces en la vida cotidiana insular.

Lejos de obedecer a factores exclusivamente deportivos, el avance del fútbol como fenómeno de masas en el archipiélago fue tributario, como sucede en todos los procesos sociales, de unas mejoras contextuales que, en el caso que nos ocupa, fueron propiciadas por los nuevos tiempos traídos por el llamado plan de estabilización de 1959. En efecto, cuando el CD Tenerife ascendió a la primera división nacional, las islas ya estaban acusando lo que, a remolque del desarrollo del turismo de sol y playa, ha sido catalogado como el mayor cambio estructural de su formación social desde la incorporación, allá a finales del siglo XV, a la Corona de Castilla. Así, conforme avanzaron los años sesenta, el desarrollo urbanístico, el éxodo rural, la reapertura al exterior, el incremento de los tiempos de ocio y, en definitiva, las mejoras del nivel de vida traídas por el crecimiento económico, crearon el caldo de cultivo idóneo para que el fútbol se agenciara una creciente masa de seguidores, aunque todavía muy desigual, tanto geográfica como socialmente, por la persistencia de las estructuras tradicionales en las zonas ajenas al boom turístico (Macías \& Rodríguez, 1995: 420-425). Al feliz maridaje fútbol / radiodifusión contribuyeron la progresiva extensión del tendido eléctrico y la instalación de otras tres emisoras en las localidades de La Orotava, Güímar y Santa Cruz de La Palma en 1960; así como el despegue de las audiciones individuales por la llegada de los transistores de pilas ${ }^{9}$ y la frescura y naturalidad con la que se cubrían tales espacios frente al tono grave y solemne de la locución de la época (Yanes, 2013: 155-175). Todo ello, también tuvo una lectura centrípeta, hacia dentro, tanto desde el punto de vista del desarrollo de las competiciones regionales como del seguimiento de estas por las diversas emisoras con el apoyo de los aficionados que, por teléfono, asumieron las corresponsalías en los distintos pueblos.

Al margen del fútbol, las modalidades más atendidas por las emisoras isleñas en estos años fueron el boxeo, al calor de la irrupción de Sombrita, Kid Tano y otros púgiles destacados en el archipiélago, y el ciclismo, este a raíz de la sonada victoria de Bahamontes en el Tour de Francia de 1959. En el deporte del pedal, el evento cumbre del año era la Vuelta a Tenerife, que empezó a organizarse a raíz del triunfo, tan jaleado por el régimen como propio, del corredor toledano en París. Para cubrir su

\footnotetext{
${ }^{9}$ Aunque los anuncios de los transistores a pilas aparecieron en la prensa madrileña a inicios de los años cincuenta (Balsebre, 2002: 334-336), no fue hasta una década más tarde cuando el invento empezó a generalizarse en Canarias, al calor de la bonanza económica, con la consiguiente llegada de la radio a los propios campos de fútbol.
} 
desarrollo, las emisoras y los periódicos enviaban a sus reporteros en automóviles detrás del pelotón para, desde las centralitas de la compañía telefónica en los pueblos, ${ }^{10}$ dar cuenta del desenlace de las sucesivas etapas a los estudios y redacciones correspondientes, comitiva a la que, desde 1963, se sumó algo así como la primera unidad móvil desplazada por una emisora isleña para cubrir el evento, cuando el locutor de La Voz del Valle, Carlos Argüelles, habilitó con varios aficionados de La Orotava una furgoneta con su rótulo correspondiente (Yanes \& Rodríguez, 2007: 186188). Los tiempos dedicados a las restantes modalidades deportivas cultivadas en la época, aunque normalmente inferiores a los de las citadas, variaban de unas emisoras a otras en función, no sólo de las especificidades del emplazamiento y de la pertenencia a una u otra cadena sino, también, de los gustos personales del encargado de la sección porque, como dijimos, la competencia por la audiencia estuvo ausente del medio en el franquismo.

Desde que Radio Juventud de Canarias empezó a ofrecer Domingo deportivo español como una estación-escuela más de la Cadena azul de radiodifusión (CAR), Mínguez asumió la corresponsalía en Tenerife del célebre programa que, desde $L a$ Voz deMadrid, llevaban Matías Prats, Martín Navas y Enrique Mariñas. Dejando en evidencia lo lejanas que todavía eran percibidas las Islas Canarias en la península, cuando Matías Prats hacía referencia a Radio Juventud de Canarias y a Radio Atlántico de Las Palmas solía decir que conectaba, nada menos que, con «los confines del Atlántico», como si el archipiélago estuviera en la Patagonia.

\section{El fútbol en las emisoras de las localidades interiores del archipiélago}

Por razones obvias, las dificultades para ofrecer la actualidad deportiva en las estaciones montadas a mediados de 1960 en las localidades de La Orotava, Güímar y Santa Cruz de La Palma eran mucho mayores, en coherencia con los inferiores recursos disponibles y las mayores limitaciones contextuales. Con ese denominador común, las diferencias de estas tres nuevas propuestas derivaron de la orientación específica de la cadena a la que pertenecía cada una de ellas, de las expectativas y tradiciones de sus municipios e, incluso, del perfil de los encargados de esta parcela de la programación. A esa incipiente pluralidad contribuía la inusual libertad que había para elaborar las crónicas deportivas en una época en la que reinaba la más absoluta y empobrecedora unanimidad en todas las vertientes de la vida social, tal y como dejaron patente los

\footnotetext{
${ }^{10}$ Con tales procedimientos, Radio Nacional de España había cubierto la Vuelta a España una década atrás (Balsebre, 2002: 340).
} 
aficionados en la prensa de la época a propósito de las contradictorias valoraciones que escuchaban, en función de si la retransmisión era propia o reproducida de una emisora peninsular, de los partidos del CD Tenerife, cosa que también sucedía en la prensa. El hecho de que hasta una modesta estación alegal montada por los padres dominicos en la basílica de Candelaria tuviera a mediados de los años sesenta dos programas deportivos, uno a las nueve de la mañana del domingo, que servía de "cartelera deportiva», y otro a las diez de la noche del lunes, en el que se ofrecía un balance de la jornada del fin de semana, redunda en la magnitud del terreno que, por entonces, había conquistado un tema tan pasional como el que nos ocupa en la agenda de las ondas hertzianas.

En el caso de La Voz delValle de La Orotava, perteneciente a la Cadena de Emisoras Sindicales, la parcela deportiva fue confiada a un conocido ex-árbitro de fútbol y aficionado al ciclismo de la zona, Carlos Argüelles, quien afrontó el reto con dos espacios: Semanario deportivo, luego titulado Gaceta deportiva, que estaba en antena los jueves por la noche; y Antena olímpica, que salía al aire las tardes de los domingos, en coincidencia con la disputa de los partidos de fútbol de las ligas nacional y regional. Al igual que hicieran en un principio las emisoras de la capital provincial, el procedimiento artesanal $y$, al amparo de la permisividad reinante, irregular para poder seguir los partidos de la primera y segunda división partía de un aparato receptor de onda corta capaz de captar la oportuna señal de la península, a través del cual Argüelles seguía el "minuto y resultado» de todos los encuentros para, desde que se producía alguna novedad, ofrecer la información pertinente a la audiencia como propia. Y al igual que hiciera su colega de Radio Juventud de Canarias, las noticias desde los distintos terrenos de juego las ofrecía con las mismas argucias, esto es, tras escuchar por su cuenta el anuncio de la conexión, se apresuraba a decir ante el micrófono el típico "a continuación conectamos con el estadio...», como si la indicación la diera él a los técnicos desde el estudio de La Voz del Valle, para a continuación dejar salir al aire la intervención del enviado especial de la emisora pirateada al lugar de los hechos (Yanes \& Rodríguez, 2007: 180-182).

Para dar cuenta del marcador y los incidentes más relevantes de los partidos que el CD Tenerife jugaba en la isla, Argüelles tenía a mano otros recursos no menos insólitos desde las perspectivas actuales, dada la enorme competitividad en la que están inmersos los medios hoy en día. En efecto, además de ir detallando la evolución del resultado con las estrategias fraudulentas reseñadas, cuando llegaba el descanso llamaba por teléfono a la sede de Radio Juventud de Canarias o, en el caso de surgir algún problema, de Radio Club Tenerife, desde donde lo ponían en contacto, a través de las líneas microfónicas tendidas hasta el estadio Heliodoro Rodríguez López, con el locutor que estaba radiando el partido in situ, quien de manera desinteresada le resumía el desarrollo de la primera parte. Los únicos partidos que La Voz del Valle servía con crónicas propias eran los disputados por los equipos de la comarca en sus 
respectivos terrenos de juego, cuyos detalles hacían llegar algunos aficionados desde las centralitas telefónicas de los municipios para que, luego, fueran leídos ante el micrófono por el locutor que estuviera de servicio. Entre los colaboradores en las categorías juveniles se contó el por entonces adolescente Juan Cruz Ruiz, cuando vivía en el Puerto de la Cruz, para quien tal actividad supuso algo así como el bautizo a su larga y fecunda labor periodística y literaria. ${ }^{11} \mathrm{~A}$ la conclusión de la jornada comenzaba, a partir de las 19:00 horas, el Marcador, un espacio complementario al vespertino en el que se ofrecía un balance de lo acontecido, tanto de la liga nacional como de las competiciones insulares, con los comentarios, la quiniela y las clasificaciones correspondientes. Para hacerse con los datos del fútbol regional, Argüelles también llamaba por teléfono al periódico El Día de la capital provincial, cuyos redactores le facilitaban la información oportuna, asimismo, sin contraprestación alguna.

Mención especial por enriquecer con más detalles el quehacer del medio en la época, merece la manera en la que la emisora norteña cubrió una de las travesías a nado que, desde 1955, se celebraban por entonces el Día de Reyes en el puerto de la capital provincial. En efecto, enterado a la conclusión de la prueba del resultado y las principales incidencias por una llamada telefónica que hizo al periódico El Día, Argüelles luego dramatizó ante el micrófono, como si estuviera presenciando los hechos en directo, el desarrollo de la competición con el desenlace correspondiente. ${ }^{12}$ Tales irregularidades, lejos de ser privativas de las islas, estaban extendidas por todas las emisoras del Estado incluyendo las mejor dotadas y, además, los temas más serios, tal y como ilustra el modo en el que Radio Nacional de España cubrió en 1959 la visita del presidente norteamericano Eisenhower a Madrid, en la que, al carecerse todavía de equipos móviles, dos locutores describieron el traslado del cortejo presidencial desde el aeropuerto de Barajas al palacio de El Pardo siguiendo un guión escrito previamente en el que se simulaba la observación directa de los hechos (Balsebre, 2002: 358-359).

En lo que a la otra emisora sindical de la provincia se refiere, La Voz de la Isla de LaPalma, el responsable de la parcela deportiva fue Pedro Cobiella Cuevas, hijo del influyente abogado local Luis CobiellaZaera y uno de los principales promotores, con su hermano mayor Luis, ${ }^{13}$ de la única estación isleña ajena a las dos islas centrales del

\footnotetext{
${ }^{11}$ Entre cuyos hitos se cuentan su participación en la fundación del diario El País, el desempeño de la dirección de la editorial Alfaguara, la veintena de libros, entre novelas y ensayos, publicados hasta el momento y su asidua presencia en las tertulias de radio y televisión más relevantes.

12 Detalles suministrados por el propio Agustín Argüelles en la entrevista en profundidad celebrada, en presencia del profesor Rodrigo F. Rodríguez, el 15 de febrero de 2007.

${ }^{13}$ Licenciado en Ciencias Químicas, músico y poeta, el polifacético Luis Cobiella Cuevas habría de asumir, tras la implantación de la democracia, el cargo de Diputado del Común (el equivalente isleño del Defensor del Pueblo) y recibir, en reconocimiento a su fructífera trayectoria, el Premio Canarias 2002.
} 
archipiélago en el franquismo. En este caso, el referente principal de las informaciones era la fuerte rivalidad existente entre el CF Mensajero y la SD Tenisca, los dos equipos de la capital insular, más aún desde la incorporación de ambos, en 1962, a la primera categoría del fútbol regional. Sobre tales bases, la oferta de la programación constaba de dos espacios diarios, uno de sobremesa y otro nocturno, a los que pronto se unieron las retransmisiones en directo de los partidos más decisivos cuando los equipos palmeros viajaban a Tenerife o Gran Canaria, no así de los que jugaban en el recinto local de Bajamar, con el que las conexiones en directo eran muy esporádicas y problemáticas, dado que hasta los años setenta se careció de una línea telefónica propia, para propiciar la mayor concurrencia posible de público (Yanes \& Hernández, 2011: 186-195). En cuanto a la actualidad del CD Tenerife, la UD Las Palmas y, en general, las ligas de primera y segunda división nacional, tras una primera etapa en la que se informaba a posteriori, a través de la lectura de la prensa y la captación de alguna señal de onda corta de la península con los típicos recursos de la época, la emisora empezó a conectar desde octubre de 1964 con La Voz de Madrid para ofrecer el célebre Domingo deportivo español.

En el caso de Radio Popular de Güímar, el capítulo deportivo fue, y con mucha diferencia, el que más interés suscitó de la programación en toda el área geográfica cubierta por la señal, incluyendo la capital provincial, donde era más oído que los espacios del género de Radio Club Tenerife y Radio Juventud de Canarias. El artífice del éxito fue el joven licenciado en Derecho, y miembro inicial de la junta directiva de la estación sureña, José Ramos, cuya formación universitaria, su timbrada voz y, sobre tales bases, sus apasionadas, incisivas y críticas intervenciones, evidentemente, dentro de los límites tolerados por la dictadura, hicieron de él uno de los referentes principales para el aficionado al deporte en la isla. Entre sus iniciativas, mención especial merece la versión que del célebre programa De Amberes a Chile, emitido por Radio Nacional de España en la península, elaboró tras recabar la documentación precisa en Madrid durante el viaje que, en el verano de 1964, hizo en representación de Radio Popular de Güímar para asistir a una reunión de la cadena COPE. Pues bien, mientras uno de sus acompañantes acudía a las jornadas, José Ramos y un tercero se encaminaron a la sede de Radio Nacional de España, donde se hicieron con los guiones originales escritos a máquina, y a continuación a una cafetería de la Gran Vía siguiendo las indicaciones recibidas, en la que solían reunirse las figuras más destacadas del fútbol español, en donde entrevistaron y grabaron, entre otros, a los presidentes de la Federación Española y del Real Madrid, Raimundo Saporta y Santiago Bernabéu, al entrenador Eduardo Toba, al periodista Pedro Escartín y al futbolista Miguel Muñoz.

Nada más regresar a Canarias, José Ramos movilizó al personal que colaboraba en su programa titulado, como el de La Voz del Valle, Antena Olímpica para, al cierre de las emisiones del día, grabar con tan preciado material, en sesiones nocturnas que solían concluir a la una o las dos de la madrugada, una recreación de los sucesivos capítulos 
que, en su día, habían salido al aire en la península bajo el mismo título, De Amberes a Chile. La audaz propuesta, ante los precarios recursos de las emisoras isleñas, causó un enorme impacto entre los profesionales del medio y los aficionados al deporte en la isla, dado que por entonces los programas de producción interna no solían rebasar los límites del territorio insular ni, mucho menos, contener intervenciones de personajes tan destacados en el panorama estatal como los entrevistados en la capital del Estado. $^{14}$

\section{La pujanza del fútbol en la radio isleña tras el embate de la televisión}

La propuesta deportiva de producción propia de las emisoras isleñas quedó obsoleta desde que el Centro Emisor del Atlántico de Radio Nacional de España, puesto en marcha en el período estival de 1964, empezó a emitir todos los días en conexión directa con Madrid, antes del último Diario hablado, la innovadoraRadiogaceta de los deportes, ${ }^{15}$ con un despliegue de medios a escala estatal desconocido hasta entonces (González Manrique, 1993). La previa inauguración, en febrero del mismo año, de Televisión Española en Canarias, con la subsiguiente emisión semanal de un partido de fútbol de la primera división, aunque sin competir con la radio porque estaba en pantalla los lunes en diferido, ${ }^{16}$ contribuyó a acercar aún más la alta competición al archipiélago, incluso, en el ámbito internacional, porque pronto se sumaron los encuentros más decisivos de los torneos europeos y de la selección nacional. Para ilustrar la envergadura del cambio que experimentó el consumo de fútbol en la isla, basta con traer a colación la enorme expectación que diez años atrás, cuando Radio Club Tenerife era la única estación emisora, había levantado por su excepcionalidad la retransmisión, según anunció el vespertino La Tarde (1954, 16 de marzo), a través de Radio Sevilla bajo el patrocinio de una casa comercial, del célebre España-Turquía disputado en el Estadio Olímpico de Roma con una plaza en juego para el campeonato mundial que, a la postre, se saldó con una de las mayores decepciones para los aficionados españoles.

\footnotetext{
${ }^{14}$ Detalles suministrados por el propio José Ramos González en la entrevista en profundidad celebrada el 21 de junio de 2007.

${ }^{15}$ Espacio deportivo de información y opinión ajeno a las retransmisiones en directo y a los centrados en los partidos, tanto antes (la previa) como después (la crónica) de su celebración, en los que expertos y protagonistas comparten micrófono (Pacheco, 2012: 275).

${ }^{16}$ A tal fin, se filmaban «en 16 milímetros las imágenes televisadas a través de un aparato conectado a un monitor de salida justamente sincronizado con la frecuencia de la imagen televisiva. El artilugio se denominaba kinescopio» (Bonaut, 2012: 259) y el producto era enviado por avión a Canarias, donde se emitía los lunes en diferido.
} 
Las penurias de las estaciones insulares en los nuevos tiempos, fraguados por el crecimiento económico de los años sesenta a remolque del turismo, se agigantaban en los programas de producción interna ajenos al deporte porque estos, además de la dura competencia de los de Radio Nacional de España, acusaron directamente la audiovisual. Tal fue así porque el impacto de la televisión se concentró en el tramo horario que hasta entonces había sido el prime-time de las ondas hertzianas isleñas, las últimas horas de la tarde y primeras de la noche, donde se adueñó, de un día para otro, de la audiencia y, con ello, del suculento pastel publicitario (Aguado, 1992: 205) que hasta entonces había monopolizado la radio en el archipiélago. La brusca caída de los ingresos se tradujo en todas las emisoras en recortes de plantillas, pérdidas de calidad de la programación y la concentración de los esfuerzos en las horas que todavía no cubría la televisión, la mañana y la media tarde, con una propuesta dirigida específicamente al ama de casa.

En la temática deportiva, sin embargo, los espacios autóctonos salieron mejor parados al centrarse en el ámbito que no cubría Radiogaceta de los deportes, el insular, mientras las retransmisiones de los partidos seguían acaparando la audiencia porque la televisión no empezó a ofrecerlos en directo hasta $1971,{ }^{17}$ cuando a través de satélite se conectaron los estudios en Canarias con la sede central en Madrid (Aguado, 1992). Además, los aficionados que seguían las tardes dominicales las jornadas de primera y segunda división, ahora ofrecidas en conexión con las cabeceras de cada cadena, aumentaron al generalizarse las audiciones individuales por la masiva llegada de los transistores a pilas y los receptores de los automóviles al calor de la bonanza económica de los años sesenta, dado que la televisión, más que un rival, era por entonces un complemento por sus emisiones en diferido. ${ }^{18}$

En paralelo a la mayor atención al fútbol local, los programas deportivos de producción interna se abrieron cada vez más a las otras modalidades que, por las mejoras del nivel de vida, empezaron a ganarse adeptos en las islas en estos años, con unos formatos, al igual que sucediera en toda la parrilla de la programación, mucho más dinámicos, a imagen y semejanza de las propuestas que llegaban de la península. El proceso, común a todos los contenidos culturales y de entretenimiento dentro de las dificultades antedichas, no fue otra cosa que el reflejo, tanto en la agenda de los medios como en las formas de hacer periodismo, de los cambios contextuales experimentados por la sociedad insular con la terciarización de la economía a remolque de la oferta turística.

\footnotetext{
${ }^{17}$ El primer partido ofrecido por TVE fue el Real Madrid-Racing de Santander, en diferido, el 24 de octubre de 1954; y el homólogo en directo, el Real Madrid-Atlético de Madrid, el 27 de abril de 1958 (Bonaut, 2012: 256-259).

${ }^{18}$ En la península, se empezaron a televisar desde marzo de 1960 para Europa, a través de Eurovisión, los partidos de la liga de campeones del Real Madrid como local; y dos meses más tarde, a propósito de la final disputada con el Eintracht de Frankfurt, se recibieron las primeras imágenes en directo desde el exterior (Bonaut, 2012: 260 y 261).
} 
Sin duda alguna, lo que mejor ilustra hacia dónde apuntaban los nuevos tiempos fue la irrupción de la modalidad femenina en el que ya era deporte de masas por excelencia, el fútbol, cuya primera manifestación en Tenerife data de finales del verano del año 1968, cuando en las fiestas patronales de La Laguna se celebró, según informara Diario de Las Palmas (1968, 13 de julio), un encuentro entre una formación local y otra grancanaria ya consolidada. Aunque las cosas apenas habían cambiado porque la iniciativa, en lugar de ser tratada como un evento deportivo más, lo fue como una rareza antinatura, ahora, al menos, se toleraba a la mujer practicar algo que, en los años iniciales y centrales del franquismo, era inconcebible porque, según los ideólogos del régimen, el rol social de madre y esposa abnegada era incompatible con el cultivo de los deportes en los que primaban los valores catalogados como exclusivos del hombre (Gil Gascón \& Cabeza Deogracia, 2012: 205-206).

La diversificación de la agenda deportiva local dentro del fuerte predominio del fútbol, no sólo conllevó una mayor variedad de informaciones sino, al calor de la apertura del país al exterior, la inserción de algunas de estas modalidades en los ámbitos estatal y, como en el caso del boxeo, internacional, de la mano de los deportistas isleños más destacados, en un proceso en el que la radiodifusión isleña centró cada vez más su quehacer en las vertientes de la realidad menos apropiadas para la televisión. Uno de los terrenos emergentes que acaparó el medio audiovisual fue el baloncesto, en auge tras el ascenso del CB Náutico a la primera división nacional, categoría en la que el cuadro tinerfeño compitió épicamente con una plantilla de jugadores canarios, entre 1966 y 1974, con los mejores equipos nacionales. Otro tanto sucedió con la lucha canaria, resurgida por entonces a remolque de la reivindicación de las señas de identidad propias que, como sucediera en todo el Estado en respuesta al centralismo franquista, sacudió las bases de la dictadura en sus últimos años. En el lado opuesto, entre las modalidades más atendidas in situ por la radio, debemos colocar el automovilismo, vivido por los coetáneos como la expresión deportiva más significativa de una época en la que el coche utilitario se generalizó entre las prósperas clases medias, cuyo primer hito fue el rally que se celebró en la isla de $1965 .{ }^{19}$ Todo ello, como dijimos, con las tardes del domingo como momento culminante, cuando todas las emisoras conectaban con sus respectivas cadenas estatales para ofrecer el desarrollo de la liga nacional de fútbol y, al término de la jornada, profundizaban en la trayectoria del CD Tenerife y las categorías regionales.

Sobre tales premisas, la iniciativa radiofónica que mejor supo adaptarse a los tiempos del tardofranquismo fue laradio-participación ${ }^{20}$ con la que el director de Radio Juventud de Canarias, Agustín García Gómez, consiguió mantener a flote a la estación-

\footnotetext{
${ }^{19}$ Los detalles de todas estas iniciativas nos han sido suministrados por las fuentes orales citadas tras contrastar sus datos entre sí y, todos ellos, con los obtenidos en la documentación consultada.

${ }^{20}$ Los artífices de la fórmula se hicieron merecedores de un Premio Ondas en 1975.
} 
escuela en aquellos años tan difíciles para el medio. La novedosa propuesta giraba en torno al segmento juvenil de la audiencia, sobre el que basculó todo el quehacer del ente a costos muy bajos, desde la elaboración a la difusión del mensaje radiofónico, pasando por la implicación como oyentes a través de votaciones e intervenciones en los espacios abiertos al público. El drástico cambio de la programación, favorecido por el paulatino retroceso de la propaganda del régimen y la distensión de la censura conforme perdían fuerza las ondas hertzianas, conllevó la mayor espontaneidad de la locución y la supresión de los espacios más tradicionales. En el caso del capítulo deportivo, el colectivo de jóvenes encargado de su producción, el Grupo XDC, lo hizo con tanto acierto que convirtió su quehacer en el principal reclamo para el público a partir de cinco espacios diferentes, con sus franjas horarias y sintonías correspondientes, dos diarios de mediodía y noche, uno el sábado en la sobremesa y dos dominicales de mañana y tarde-noche, sin contar las retransmisiones en directo de los eventos del fin de semana. La rompedora iniciativa, coordinada en un principio por el veterano Mínguez, se abrió a una pléyade de colaboradores regionales a través de las líneas telefónicas $y$, anunciando los nuevos tiempos que se avecinaban para la mujer, a una pequeña representación femenina. Con tales actividades y el paralelo afloramiento de la controversia en las crónicas deportivas que, hasta entonces, había ocultado el clima de camaradería reinante en la dictadura, la vieja estación-escuela formó a Domingo Álvarez ${ }^{21}$ y a otros periodistas deportivos que habrían de destacar en los años de la democracia, lo que significa que esta había adquirido en el tardofranquismo la orientación antagónica a la fundacional (Yanes, 2009: 206-209).

\section{Conclusiones}

La investigación ha dejado en evidencia que, incluso en los años de la dictadura franquista, cuando el sistema comunicativo español estaba uniformizado por un férreo centralismo, el quehacer de la radiodifusión isleña evolucionó con unas particularidades que no encajan en la dinámica expuesta en las obras elaboradas sobre el conjunto de la radiodifusión española. Factores geográficos como la lejanía y la insularidad, junto a otros no menos estructurales como la tradicional apertura al exterior de la economía y la idiosincrasia canarias, se encargaron de gestar en el archipiélago, a pesar del afán autárquico y unificador del régimen, el subsistema comunicativo más singular de la España franquista. Bajo tales premisas, la etapa más

\footnotetext{
${ }^{21}$ El excelente quehacer profesional de Domingo Álvarez Febles, actual director de Radio Nacional de España en Canarias, ha quedado testimoniado en las continuas llamadas que ha recibido de Madrid desde inicios de los años noventa para cubrir las olimpiadas, los campeonatos mundiales de fútbol y baloncesto, los juegos del Mediterráneo y, en definitiva, todos los eventos deportivos internacionales con presencia española.
} 
boyante de las ondas hertzianas isleñas transcurrió, sin que pueda hablarse de la "edad de oro» por la ausencia de libertades, en el quinquenio comprendido entre 1959 y 1964, esto es, con retraso en relación a Madrid y, más aún, los enclaves punteros del mundo occidental. ${ }^{22}$ La entrada en vigor del llamado Plan de Estabilización, con la consiguiente introducción de la economía insular en una coyuntura alcista a remolque del turismo, fue el motor de la favorable coyuntura al propiciar la extensión del tendido eléctrico, la instalación de nuevas emisoras, el incremento de los ingresos publicitarios del sector y la venta masiva de aparatos receptores. Pero la favorable coyuntura sólo fue flor de un día porque a partir de febrero de 1964 la televisión empezó a desplazar, con su espectacular irrupción, a la radio de su privilegiada posición en el sistema comunicativo de las Islas Canarias. Al margen de la demora con la que llegaron las innovaciones de los enclaves más desarrollados del Estado, el caso isleño se distinguió por la presencia de una serie de especificidades que dejaron su impronta en todos los capítulos de la parrilla de la programación incluyendo, como no podía ser de otra manera, el fútbol.

En el primer franquismo, la información deportiva estuvo recluida en el entorno insular hasta los ascensos a la segunda división nacional, en 1950, de la UD Las Palmas y, tres años más tarde, del CD Tenerife, los cuales propiciaron la ampliación del ámbito de actuación de las emisoras isleñas al resto del Estado. Aún así, la desconexión con la península, las estrecheces económicas de la época y la existencia en la zona occidental del archipiélago de una sola estación privada que todavía no pertenecía a la SER, Radio Club Tenerife, dificultaban sobremanera una labor informativa que, las tardes dominicales, se solventaba con la apropiación de alguna de las señales ajenas que llegaban de Madrid ante la actitud tolerante de las autoridades locales. El panorama mejoró con la posterior inauguración de Radio Juventud de Canarias (1955-1978) y, a inicios de la bonanza económica, de otras tres emisoras institucionales, La Voz del Valle (1960-1965), Radio Popular de Güímar (1960-1969) y La Voz de la Isla de La Palma (1960-1978), ${ }^{23}$ dado que todas ellas contaban con el apoyo en Madrid de la emisora central de la cadena a la que pertenecían. El paralelo ascenso del CD Tenerife a la primera división en 1960 y, al calor de la mejora del nivel de vida, la generalización de los transistores a pilas, con la consiguiente salida de la radio de los hogares para dejarse oír en todas partes, incluidos los estadios, fueron los otros factores que consolidaron al fútbol como reclamo por excelencia de la audiencia masculina en un

\footnotetext{
${ }^{22}$ Mientras en las zonas más desarrolladas de la España franquista la etapa más pujante de la radio, con el ingrediente del fútbol potenciado desde el poder por su función «anestesiante» en la sociedad, data de los años previos a la irrupción de TVE en 1957 (Balsebre, 2002: 325-342), la «edad de oro» del medio en los países punteros de mundo occidental, en los que la televisión se había generalizado desde el cese de la II Guerra Mundial, fueron los años 30 (Albert \&Tudesq, 2001: 35-54).

${ }^{23}$ Junto a las emisoras citadas, en el franquismo emitió en Tenerife, aunque con escasísima penetración por la carencia de receptores capaces de captar tal tipo de señal, La Voz de Canarias (1963-1965) de la CES en frecuencia modulada (Yanes, 2007).
} 
momento en el que las ondas hertzianas isleñas se habían convertido en el medio de referencia del sistema comunicativo insular. La galopante crisis en la que quedó inmersa la radiodifusión insular tras la puesta en marcha de Televisión en Canarias en febrero de 1964, apenas se dejó notar en el fútbol, toda vez que los partidos televisados de la primera división se ofrecieron en el archipiélago en diferido hasta 1971, cuando los estudios isleños se conectaron, vía satélite, con la sede central de Madrid (Aguado, 1992). Por entonces, la radio española empezaba a recuperar posiciones al calor de la tímida distensión de la censura, tal y como ilustra la emisión del espacio Hora veinticinco de la SER, por la creciente contestación al régimen de los sectores intelectuales, estudiantiles y obreros.

En el caso insular, un granito de arena en pos de la búsqueda de nuevos formatos para acomodar las ondas hertzianas a los nuevos tiempos fue la innovadora propuesta de la radio-participación de la estación-escuela de la $C A R$, con el deporte, en general, y el fútbol, en particular, como principal referente de la audaz propuesta. Con ello, no se hizo otra cosa que seguir la tradición, porque esta fue la temática que mejor parada salió de la travesía del desierto que supuso para la radiodifusión isleña el tramo comprendido entre la irrupción de la competencia audiovisual, en 1964, y los inicios de la transición democrática, cuando la radio empezó a reclamar, esta vez al mismo tiempo en Canarias que en el resto del Estado, el papel que le corresponde en toda sociedad democrática.

\section{Referencias bibliográficas}

AGUAdO MONJAS, G. (1992): La Televisión Pública en Canarias, tesis doctoral, Departamento de Periodismo IV de la Facultad de Ciencias de la Información de la Universidad Complutense de Madrid.

AGUIRRE ROJAS, C. A. (2014): Microhistoria italiana: modo de empleo, Madrid, Montesinos.

ALBERT, P. \& TUDESQ, A.J. (2001): Historia de la radio y la televisión, Méjico, Fondo de Cultura Económica.

BALSEBRE, A. (2002): Historia de la Radio en España (1939-1985), Madrid, Cátedra.

BONAUT, J. (2012): «Retransmisiones futbolísticas televisivas en España: perspectiva histórica de una relación de necesidad (1956-1988)», en Historia y comunicaciónsocial, no 17, Universidad Complutense, pp. 249-268. 
BREISACH, E. (2009): Sobre el futuro de la Historia. El desafío posmodernista y sus consecuencias, Valencia, Universidad de Valencia.

CHECA GODOY, A. (2009): «Prensa y radio en Sevilla del tardofranquismo (19511975)», en Langa Nuño, C., Romero Domínguez, L.R. y Ruiz Acosta, M.J. (coords.), Un siglo de información en Sevilla (prensa, radio y televisión): 1909-2009, Universidad de Sevilla, pp. 165-206.

EZCURRA, L. (1974): Historia de la radiodifusión española. Los primeros años, Madrid, Editora Nacional.

GIL GASCÓN, F. \& CABEZA DEOGRACIA, J. (2012): «Pololos y medallas: la representación del deporte femenino en NODO (1943-1975)», en Historia yComunicación Social, no 17, Universidad Complutense, pp. 195-206.

GONZÁLEZ MANRIQUE, J.J. (1993): Los mensajes informativos de Radio Nacional de España en Canarias: radio regional, radio local (1982-1992), tesis doctoral, Facultad de Ciencias de la Información de la Universidad de La Laguna.

GOROSTIAGA ALONSO-VILLALOBOS, E. (1976): La radiotelevisión en España (Aspectos jurídicos y derecho positivo), Pamplona, Universidad de Navarra.

GUERRA PALMERO, R.A. (2006): Sobrevivir en Canarias (1939-1959). Racionamiento, miseria y estraperlo, Canarias, Ediciones Idea.

LEVI, G. (1999): «Sobre microhistoria», en Burke, P. (editor), Formas de hacer Historia, Madrid, Alianza Universidad, pp. 119-142.

MACÍAS HERNÁNDEZ, A.M. \& RODRÍGUEZ MARTÍN, J.A. (1995): «La economía contemporánea, 1820-1990», en Antonio de Bèthencourt (editor): Historia deCanarias, Las Palmas, Cabildo de Gran Canaria, pp. 369-398.

MORAGAS, M. (1994): «Deporte y medios de comunicación. Sinergias crecientes», en Telos, no 38, junio-agosto 1994.

PACHECO BARRIO, M.A. (2012): "Los programas deportivos radiofónicos en la medianoche: la supremacía del fútbol en los contenidos», en Historia ycomunicación social, no 17, Universidad Complutense, pp. 269-295.

PUJADAS MARTÍ, X. (coord.) (2011): Atletas y ciudadanos. Historia social del deporte en España (1870-2010), Madrid, Alianza Editorial.

SINOVA, J. (1989): La censura de Prensa durante el franquismo (1936-1951), Madrid, Espasa-Calpe. 
SUÁREZ BOSA, M. (1996): Recuperación y crisis de la economía canaria (1920-1936), Canarias, Editorial Benchomo.

YANES MESA, J.A. (2007a): Los orígenes de la COPE en Canarias. "Radio Popular de Güímar», 1960-1969, Canarias, Ediciones Baile del Sol.

- (2007b): «La Voz de Canarias (1963-1965) en frecuencia modulada: un anacronismo radiofónico por anticipación en los años centrales del franquismo», en Boletín Millares Carlo, no 27, Las Palmas, pp. 105-118.

- (2009): Las ondas juveniles del franquismo. "Radio Juventud de Canarias», 1955-1978, Canarias, Ediciones Baile del Sol y Dirección General del Libro, Archivos y Bibliotecas del Gobierno de Canarias.

- (2010): Los orígenes de la radiodifusión en Canarias. "Radio Club Tenerife», 1934-1939, Canarias, Ediciones Baile del Sol y Dirección General del Libro, Archivos y Bibliotecas del Gobierno de Canarias.

- (2012) La radiodifusión privada en Canarias durante el franquismo. "Radio Club Tenerife», 1939-1975, Canarias, Ediciones Densura.

- (2013): "La locución radiofónica en Canarias durante el franquismo», en Revista Internacional de Historia de la Comunicación $(R I H C)$, no 1, Universidad de Sevilla, pp. 155-175.

- \& RODRíGUEZ, R.F. (2007): La radiodifusión sindical del franquismo. "La Voz del Valle» en las Islas Canarias, 1960-1965, Canarias, Ayuntamiento de La Orotava, Cabildo de Tenerife y Dirección General del Libro, Archivos y Bibliotecas del Gobierno de Canarias.

— \& HeRnÁNDEZ CABRERA, E. (2011): "La Voz de la Isla de La Palma», 19601978. La radiodifusión del sistema comunicativo más singular de Canarias en el franquismo, La Palma, Ediciones Alternativas. 